\title{
Interactive White Boards in Preschool and Primary Education
}

\author{
http://dx.doi.org/10.3991/ijoe.v10i4.3754 \\ Athanasios S. Drigas and George Papanastasiou \\ NCSR DEMOKRITOS, Institute of Informatics and Telecommunications, Net Media Lab, Athens, Greece
}

\begin{abstract}
Technologies within the domain of interactive, remote and on line science which are extensively adopted in education's everyday life are interactive whiteboards and related applications. Interactive whiteboards indicate positive effects on students' learning and instructors' teaching, promoting whole class teaching. In this review-paper we cope with the studies that explore the integration of IWBs in preschool and primary education in the last decade (20042013). Research has shown that interactive whiteboards are able to keep students involved and foster their attention in every aspect of the curriculum, much easier than without it. This technology has proven its value added to students and teachers in different facets of teaching and learning, in literacy, in mathematics, in science, in physics, its impact on English Language Learners, on relations and learning, on the use of IWBs by kindergartners, professional development of teachers, pedagogical orchestration, classroom dialogue and pedagogic practice.
\end{abstract}

Index Terms-IWB, interactive, multimodal teaching, collaboration, e-teaching, e-learning

\section{INTRODUCTION}

IWBs introduce the education community to an important point of principle that we should be talking about 'interactive technologies' that use multimedia resources, support the planning and development of resources, and allow improved presentation by the teacher and/or pupils. Also accommodate different learning styles, motivate and engage pupils by their coming up to the IWB and interact with the program through the IWB and model ICT skills. The added value becomes a lot clearer if we focus on teaching, where the IWB helps to sustain the pace of the lesson and allows a seamless flow from one teaching point to the next [1].

The 'boon' of the IWB technology lies in its unique features that foster pupils' learning through multimedia and multi-sensory presentation, resulting in improved motivation and affect, promoting both technical and pedagogic interactivity in whole class interactions [2].

There might be a 'tipping point' of technical competence and pedagogical interactivity, before teachers and their classes can fully exploit these technologies in ways that promote student learning [3].

Interactive teaching and learning based on constructivist theories, by Jean Piaget and Lev Vygotsky, have shaped how teachers approach instructional design and explore options which could aid in knowledge retention and inspire the learner to participate more [4].

Blackboard was introduced in 1801 and became so pervasive and its use so normalised that it took 200 years to begin to be superseded by another whole-of-class technology board, namely 'Interactive white board'. It is indicated that only if the vast majority of the teachers in a school are using the digital technology effectively and not improving the ways of the old, can quality teaching and improved student attainment be expected [5].

One of the defining skills of quality teaching offered by an interactive whiteboard is the digital convergence where students can interact with the concepts, content and context of a media rich, multi-literacy teaching environment driven by the teacher's ability to manage classroom activities, use of ICTs and enhance their existing professional skills [6].

Quality teaching is the teacher's ability to manage classroom IWB's activities, which are following closely the framework of Gagné's nine events of instruction. IWB offers many features that are used to address each of the nine steps: Gaining Attention, Informing the Learner of Objectives, Stimulating Recall of Prior Knowledge, Presenting the Stimuli, Providing Learner Guidance, Eliciting Performance, Providing Feedback, Assessing Performance, Enhancing Retention and Transfer [7].

\section{IWBS' AdDED VALUE TO STUDENTS}

\section{A. Implementation in Literacy.}

Potentially IWBs can offer a multimodal approach to teaching literacy which, in practice, suggests that this potential is beginning to be realised. Also, in order to help more teachers towards effective use of the IWB, it is better to follow a 'bottom-up' approach in their transmission training, which is more practitioner focused, than a 'topdown' commercial one [8].

While some children benefited from the approach, of using interactive whiteboard technology and interactive talking books in whole-class writing lessons, teaching children to write through examination of professional models of writing in whole-class lessons did not promote the most effective learning. Children should be asked to write on topics that are meaningful to them, taking into account their experiences and interests [9].

An important finding in Kate Wall's, S. Higgins' and H. Smith's enquiry is that there is an obvious visual and verbal-social state of learning, between IWBs and pupils' views of interacting, in the teaching and learning processes. IWBs can be effective tools for initiating and facilitating pupils' understanding, remembering, and thinking, especially where pupil involvement and use of the board is taken place. Color and movement in particular, is seen by the pupils to be motivating and reinforces concentration and attention [10].

Damian Maher (2011) demonstrates the use of an ebook through IWB's facilities and states that through the use of text, sound, images, color and animation a rich tapestry of semiotic resources was made available to allow students to appreciate, interpret and review texts. 


\section{PAPER}

He concludes that not only does the IWB facilitate an increased range of modes, allowing students with different learning styles and educational needs to participate, it also allows for a greater level of interactivity than a data projector or traditional book [11].

\section{B. Implementation in Mathematics.}

Students' attitudes towards the use of IWB in mathematics classes is at a medium level, which can be interpreted as positive as they were introduced with this new technology for the first time and students see the IWB as a tool which increases their interest and facilitates learning. It's characteristic that more than half of the students stated that they would like to do all their math lessons using the IWB, because the IWB provided the advantage of solving more questions, saving time and providing visuals [12].

The children, in a study presented by Merilyn Taylor Ann Harlow, Michael Forret (2010), used the IWB space to co-construct knowledge as they participated in socially shared cognition. The IWB was pivotal in supporting the development of task-related talk for the children, while the teachers had set up their classroom learning environments and modeled behaviors to encourage a culture of listening to and respecting others' views [13].

In conjunction with this, the teacher must select the solutions that are discussed, analyzed, and developed further in the IWB, and steer the discourse conducting a discussion involving the entire class. The survey results showed that the students perceived they could discuss and communicate more often and better with both their teacher and classmates than in regular math lessons [14].

In the research presented by B. Torff, R. Tirotta(2010) it is reported a study, where students exposed to IWBassisted lessons showed a slightly higher level of engagement in mathematics classes, relative to a control group taught without the IWB. In parallel their teachers' attitudes about the IWB were associated with slightly higher levels of motivation; in other words, teachers who strongly supported using the IWB (and likely used the technology well) produced larger motivational effects in their students [15].

\section{Implementation in Science.}

IWB can be used collaboratively in a variety of science activities closely related to familiar classroom practice and the children can engage effectively in the collective learning experience including the open-ended tasks, a series of cumulative tasks set up by the teacher and paced by the children; tasks requiring the integration of web-based materials and peripheral technologies; and investigative work requiring discussion, visual representation, and notetaking. This represents an interacting system with social, cognitive, technical, and temporal dimensions [16].

P. Warwick, Neil Mercer, Ruth Kershner, Judith Kleine Staarman (2010) examining the vicarious presence of the teacher in pupil's learning of science, suggest that the teacher remotely mediates the activity of the pupils at the board in two specific and interlinked ways. The first of these is concerned with the ways in which the pupils appropriate and use introduced rules and procedures. The second is in the ways in which the teacher uses the task structure to guide and mediate the pupils' actions, enabling them to interpret and act upon the teacher's intentions for the task [17].
Karen Murcia and Rachel Sheffield (2010) in their research suggest that teachers' effective IWB pedagogy impacts positively on the way students talk about science. Seven principles of effective interactive pedagogy focused on scaffolding deep substantial science discourse emerged from the action research: Engaging and appealing interactive displays, Accessing online information, linking in media files, interacting with online activities, constructing a series of interactive activities to develop the scientific story, Reviewing learning, Using IWB tools to increase wait time [18].

P. Warwick, Neil Mercer, Ruth Kershner (2013) aim to show how a teacher can use the cultural tool of spoken language in conjunction with another cultural tool, the interactive whiteboard, to provide effective support for children's collective learning. They are very conscious of the need to maintain a rigorous definition of 'scaffolding' whereby it reduces the degrees of freedom of a task in ways which are contingent to, and orientated to, the developing expertise of the learners, even though this scaffolding was sometimes achieved without the teacher being physically present [19].

\section{Implementation in Physics.}

Daniela Stoica, Florica Paragina, Silviu Paragina, Cristina Miron, Alexandru Jipa (2012) have tried to describe how the interactive whiteboard can be used during Physics classes, so as to value the opportunities offered by this interactive tool, while taking into account the cognitive load theory, which can provide guidelines to assist in the presentation of information in a manner that encourages learning. They concluded that the interactive whiteboard has many advantages, both for teachers and students, including the ability to manipulate objects in real time, efficiency in presenting a lesson and support for the long-term planning and use of resources as well as visual enrichment of web documents [20].

\section{E. Impact on English Language Learners}

Using an interactive whiteboard for visual presentations, interactive games, and test reviews in an ELL classroom not only help teachers create active learning environments but also assist students in practicing English in class and at home, resulting in higher test scores. In the study conducted by Jung Won Hur \& Suhyun Suh (2012), technology motivated students during the learning process and provided more opportunities for speaking and writing practice, which assisted them in improving their English proficiency. The project provided ample opportunity for students to research a topic, develop a presentation, and practice speaking skills. Regardless of its long-term effects, the incorporation of the new technology clearly helped create active learning environments. This result implies that educators should strive to find new ways to motivate students by integrating technology and creating engaging learning activities [21].

Omar S. López (2010) in his research concludes that the Digital Learning Classroom equipped with an IWB technology demonstrates its potential value, to achieve performance parity between English Language Learners and regular students. Furthermore, greater results should be expected for ELL, as teachers gain still higher levels of proficiency in using the IWB's advanced functions and find ways to engage ELL students in meaningful learning that results in higher levels of student academic achievement and challenge them to continue their studies in ad- 
vanced subjects so that they can join their peers in similar course-work-taught in the English language [22].

\section{F. Impact on Relations and Learning}

Higgins, S. E. (2010) designed a research under a pilot program and showed that students were very positive about the use of interactive whiteboards. They particularly liked the multimedia potential of the technology and that they would like it if their teachers used the interactive whiteboard more in lessons. There were overwhelmingly positive teachers' and students' perceptions of aspects affecting teaching and learning. Results suggest that the use of the interactive whiteboards did lead to significant changes in teachers' practices in the use of technology and in aspects of classroom interaction, affecting positively the learning process [23].

For this interaction to be more than superficial, learners must engage with the teaching in some meaningful manner, bringing something of them to the exchange and not merely acting as passive recipients of preformed information. It is considered that interactivity demands a grate level of active participation by learners who contribute to the development of collective understanding [24].

H. Riese et al.(2012), showed in their research analysis that peer learning activity is described as a communicative process characterised by three distinct features: (a) it relies on meditational means; (b) it needs trust and a safe social environment; and (c) it allows disagreement. All of these features may be accomplished through IWB's features, as well [25].

\section{G. The Use of Interactive Whiteboards by Kindergartners (and their Teachers)}

An exploratory case study analyzes various dimensions of problem solving, conducting a series of analogous computer programming problems, using a Logo-based environment on an IWB by 5-6 years old kindergarten children. The teacher expressed her preference in activities that engage the whole class, with the use of the IWB, in comparison to the computer corner, as she believes that this mode strengthens the collaboration and the active participation of the children and encourages extensive dialogue [26].

A. Morgan (2010) in his paper indicates the following principles in the teaching and learning of children aged three to seven years regarding the use of IWBs: Representation and organisation of ideas, visualisation and reflection on thinking, communication of ideas and collaboration, extension and communication of learning to the broader community and documentation of a more divergent form of pedagogical practice [27].

A. Harlow, Bronwen Cowie \& Megan Heazlewood (2010)focus on how the features of the IWB supported teaching actions and provided potential and structure for the children to develop their 'key competencies', working as active learners and creating a feeling of achievement or managing self.The authors demonstrate that it was the teacher's orchestration of the classroom environment, incorporating the use of the IWB, that was the key to the development of a classroom culture that includes a participatory pedagogy [28].

Kung-Teck Wong, Sharon Russo, Janet McDowal (2013) in their study showed that performance expectancy and effort expectancy were found to have a direct and statistically significant positive effect on behavioral inten- tion, meaning that student teachers will engage themselves when they are able to see the value and benefits of using IWB. Also implies that efforts to prepare new teachers to use IWBs effectively should synchronize the implementation with its pedagogical benefits. This is the first paper that investigated the acceptance and use of IWB among early childhood science student teachers based on the Unified Theory of Acceptance and Use of Technology (UTAUT) model. Hence, it provides several prominent implications for the research and practice [29].

\section{IWBS' ADDED VALUE TO TEACHERS}

\section{A. Professional Development of Teachers.}

Teachers' professional development in the use of information and communications technology should necessarily be integrated with discussion of thinking through new ideas and trying out new practices rather than focusing on technical skills alone. It is essentially the way in which the teacher constructs and guides the work at the IWB to promote collaborative interaction and learning that is important [30].

P. Serow and R. Callingham (2011) through their analysis of teacher use of IWBs in four different levels, namely Retreatism/Technical Deficiency (Level 0), Black/ Whiteboard Substitute (Level 1), Apprentice User (Level2) and Initiate User (Level 3) emphasised the need to provide sustained professional development. All teachers involved in the research expressed the view that their students' learning had motivated either using the IWB in the form of a presentation tool or using the 'fun' nature of the equipment [31].

Gary Beauchamp (2004) states that, IWB can create a new freedom in pedagogy to develop a progressive framework, or a means to deliver existing practice in another format, where teacher and pupils work together to achieve learning objectives. The technology thus becomes a liberating force and allows children to interact confidently with the IWB, developing the transition framework from beginner to synergistic user of the IWB as follows: black/whiteboard substitute, apprentice user, initiate user, advanced user, synergistic user. Teachers are able to see how this can be used to facilitate a synergy of learning, which allows them to co-construct new understanding of both subject content and pedagogy in the primary classroom. In which pupils and teacher combine joint technical skills and teachers' pedagogic vision create a new learning praxis [32].

Essam Bakadam and Mohammed J. Sharbib Asiri (2012) through their findings revealed that most teachers believe that IWB constitutes an effective and convenient way to deliver the learning content ( $90 \%$ of them agreed with the statement) and that it increases the level of classroom interaction which in turn increases the learning experience. However it is recommended that teachers using the IWB in class undergo more training so that they can become fully aware of how to optimize its use to ensure that learners are motivated and engaged. Overall, the results showed a positive attitude towards implementing the IWB, indicating that it was enjoyable as an instructional tool and technological adjunct to classroom lessons [33].

S. Hodge and B. Anderson (2007) used a qualitative, self-study methodology to explore the impact of introducing interactive whiteboard technology to a primary school classroom. Several key insights, described as 'nodal moments', provided the impetus for the teacher to review her 
practice, reconsider her students' learning approaches and becoming a much more confident user as time passed. These features site this study at the intersection between technical and pedagogical interactivity [34].

\section{B. Fostering Pedagogical Orchestration}

The characteristics of pedagogical interactivity are more important in stimulating the reflection and intentionality of higher-order learning. If these characteristics can be appropriated by learners when using ICT, we should start to see the benefits of the greater learner autonomy which ICT provides [35].

Gary Beauchamp \& Steve Kennewell (2013) revisit the analysis of how the IWB can contribute to effective pedagogy where the IWB functions as a hub for classroom activity in order to facilitate effective learning by the pupils.. The key difference is that both the teacher and pupils use the affordances of IWB for orchestration of activity, such as the accumulation of resources which are ready-tohand on the board, rather than merely using a set of unrelated tools predominantly used by the teacher [36].

IWB may be a useful heterogeneous tool kit in facilitating interactions with multiple modes of representation that engages students in a multimodal series of recaps, elicitations and reformulations. It is not that access to these modes was previously impossible for teachers, but rather that this technology makes it so easy and convenient for the teachers to deploy them as rapidly as wanted to construct pedagogic practices, communicative processes and educational goals. The IWB offers a number of presentational and ICT functions, which, taken together, offers new opportunities for fostering multifaceted pedagogic strategies [37].

F. Smith, Hardman Frank and Higgins Steve (2006) in their article argue that an IWB lesson had a faster pace, contained more whole class teaching and less group work than non-IWB lessons and this was true for both numeracy and literacy lessons. With regard to the frequency of discourse moves, the lessons which used IWBs had significantly more open questions, answers from pupils and evaluation. According to the researchers, while the emerging literature is promising and generally supportive of IWBs they do not suggest a fundamental change in teachers' underlying pedagogy and more extensive research needs to be carried out into ways of effectively supporting teachers in their professional development, in order to change traditional patterns of whole class interaction necessary for responsive teaching, to increase the opportunities for extended teacher-pupil interactions [38].

B. Sundberg, Maria Spante \& Jörgen Stenlund (2012) found in their project that the implementation process of IWBs is very technology-oriented, dependent on attitudes either being less accustomed to the digital world than the children or saw it as a way to invite the students to become active. Thus, different types of communicative approaches (dialogic-authoritative and interactive-noninteractive) emerged among the teachers regarding whether and how they used the IWBs in their lectures. What also became increasingly clear during this study was the apparent distinction between the interactive utility of the technology and teachers' part of the pedagogical applications [39].

\section{Promoting Classroom Dialogue}

IWB does offer some useful facilities for supporting children's discussion. One of these is really related to a pedagogic approach in which teachers encourage students to participate actively. This dialogic space allows them to 'scaffold' collaborative tasks by arranging material, in a specific sequence and implement a dialogic pedagogy that incorporates three aspects: IWB's use for creating joint activity, student's use of such joint collaborative activity and the teacher's use of a dialogic pedagogy organising activities [40].

Tanner H., Beauchamp G., Jones, S. \& Kennewell, S. (2010) observed that in effective learning environments, teachers and learners often moved outside the constraints of pre-determined orchestration and began to improvise, like jazz musician's unplanned improvisations in response to stimuli from other players. The dynamic and contingent properties of ICT can facilitate the exploration of ideas and improvisation by both pupils and teachers leading to effective teaching and learning [41].

Neil Mercer, Sara Hennessy \& Paul Warwick (2010) investigated how teachers could use the technical interactivity of the IWB to create interesting multimodal stimuli for whole-class dialogue. It is clear from their study that the effective use of the IWB as an educational tool is not inherent in the hardware, software or even the materials it displays. It is predicated upon the evolving pedagogy and the teacher's practical understanding of how to engage students and to help them learn [42].

\section{Influence on Pedagogic Practice (Creation, Interaction, Collaboration, E-teaching)}

The shared representation of content on the IWB potentially may be used: a) to function as a communicative and pedagogic tool in the teacher-pupil interactions, b) to encourage more interactive and non-authoritative dialogue, c) to alter well-documented features of normal classroom interaction, d) to build a shared frame of reference between teacher and children or to build common knowledge amongst members of the class and e) pursue teachers' pedagogic tools [43].

V. Armstrong et al. (2006) illustrate that through the introduction of IWBs into the classroom teachers have deepened and enhanced their own reflections on their changing pedagogic practices. Teachers and students are critical agents in mediating the software and bring a much-needed critical perspective to the research process, which relate to their previous cultures of teaching, learning and tool use [44].

Cathy Lewin, Bridget Somekh, Stephen Steadman (2008) argue that the IWB's use becomes embedded in the teachers' pedagogy as a mediating artefact for their interactions with their pupils, and pupils' interactions with one another, and this is when changes in attainment, attendance and behavior become apparent [45].

Michiel Renger, Gwendolyn L. Kolfschoten, Gert-Jan de Vreede (2008) offer a first overview of advantages and disadvantages of interactive whiteboards, providing first insights in the various settings in which they can be used to support collaborative modeling and manipulate the model directly, stimulating participation. They discuss the way IWB's are used on three different topics: the group composition, technology and modeling approach, concerning the group size, level of participation, role assignment manipulation and access rights, text and structure recogni- 
tion, storage and versioning, no process support, chauffeured and facilitated process [46].

An interactive whiteboard is a necessary component for an e-teaching approach to classroom practice. The interactivity, the tactile nature of students' interactions with the board alongside with the teacher's ability to manage classroom activities where students can interact with the concepts, content and context of the lesson, promotes an elevated level of engagement with the lesson that makes eteaching as a pedagogical approach effective in the long term [6].

\section{CONCLUSIONS}

Evidence showed that IWB's impact in the pedagogy of the class depends on teacher's fluency in the use of IWB affordances as long as whole-class use of its technology to enliven presentation, increase pupil participation and reinforce learning. Teachers are critical agents in implementing the software and in ensuring the appropriate use of the technology to promote quality interactions and interactivity, although in terms of impact on pupils' attainment the IWBs appeared to have a negligible effect [47].

The benefits of a successive adaptation of the IWB technology could be gained through a more open, collaborative and imaginative use of its affordances, taken into consideration useful insights provided by the students, into the uses of IWB and most of all through an educational climate that don't militates against increased pupil access to the technology [48].

Pupil perspectives identify the IWB's visual, aural, tactile and multimedia presentation. Thus, IWB has developed a perception as a tool for implementing engaging pedagogies and serves as a focus for communal attention, action and cognition [49].

The effectiveness of the IWB has been proven either directly or indirectly, demonstrating a number of benefits perceived for teaching including efficiency, versatility, multimodal presentation and interactivity, which are intended to be transformed into benefits for learning, such as engaging less able, longer attention span and better focus, visual and dynamic representations, motivation, pace and flow. In addition there are some others that are worthy of further investigation such as differentiation, reflection, collaboration, retention and transfer [50].

\section{REFERENCES}

[1] Paul Kelley, Guy Underwood, Franc Potter, Jane Hunter \& Sue Beveridge: VIEWPOINTS, Learning, Media and Technology, 32:3, 333-347, 2007 http://dx.doi.org/10.1080/17439880701511 164

[2] J. Smith et al. Interactive whiteboards: boon or bandwagon? A critical review of the literature. Journal of Computer Assisted Learning 21, pp91-101, 2005 http://dx.doi.org/10.1111/j.13652729.2005.00117.x

[3] Sara Hennessy \& Paul Warwick. Research into teaching with whole class interactive technologies, Technology, Pedagogy and Education, 19:2, 127-131, 2010 http://dx.doi.org/10.1080/ 1475939X.2010.491211

[4] Tara J. Brigham: Smart Boards: A Reemerging Technology, Medical Reference services Quarterly, 32:2, 194-202, 2013 http://dx.doi.org/10.1080/02763869.2013.776903

[5] Mal Lee: Interactive whiteboards and schooling: the context, Technology, Pedagogy and Education, 19:2, 133-141, 2010 http://dx.doi.org/10.1080/1475939X.2010.491215

[6] Peter Kent: Smartboards: Interactive Whiteboards in Classrooms Embedding Learning Technologies Module 13, 15th International Conference of the Society of Information Technology and Teacher Education, Atlanta USA, 2004
[7] Beth Mc Kinney, Exploring Interactive Whiteboard Use in the 4 6 grade classroom using Gagne's nine events of Instruction, A Dissertation in the Graduate School of The University of Alabama 2012

[8] Shenton, A. and Pagett, L., From 'bored' to screen: the use of the interactive whiteboard for literacy in six primary classrooms in England. Literacy, 41: 129-136, 2007 http://dx.doi.org/10.1111/ j.1467-9345.2007.00475.x

[9] Martin, S., Interactive whiteboards and talking books: a new approach to teaching children to write?. Literacy, 41: 26-34, 2007 http://dx.doi.org/10.1111/j.1467-9345.2007.00449.x

[10] Wall, K., Higgins, S. and Smith, H., 'The visual helps me understand the complicated things': pupil views of teaching and learning with interactive whiteboards. British Journal of Educational Technology, 36: 851-867, 2005 http://dx.doi.org/10.1111/j.14678535.2005.00508.x

[11] Damian Maher, Using the multimodal affordances of the interactive whiteboard to support students' understanding of texts, Learning, Media and Technology, 36:3, 235-250, 2011 http://dx.doi.org/10.1080/17439884.2010.536553

[12] Berna Tataroğlu, Ayten Erduran, Examining students' attitudes and views towards usage an interactive whiteboard in mathematics lessons, Procedia - Social and Behavioral Sciences, Volume 2, Issue 2, Pages 2533-2538, 2010

[13] Merilyn Taylor, Ann Harlow, Michael Forret, Using a Computer Programming Environment and an Interactive Whiteboard to Investigate Some Mathematical Thinking, Procedia - Social and Behavioral Sciences, Volume 8, Pages 561-570, 2010

[14] Claudio Alvarez, Sadaf Salavati, Miguel Nussbaum, Marcelo Milrad, Collboard: Fostering new media literacies in the classroom through collaborative problem solving supported by digital pens and interactive whiteboards, Computers \& Education, Volume 63, Pages 368-379, 2013 http://dx.doi.org/10.1016/j.compedu. 2012.12.019

[15] Bruce Torff, Rose Tirotta, Interactive whiteboards produce small gains in elementary students' self-reported motivation in mathematics, Computers \& Education, Volume 54, Issue 2, Pages 379383, 2010 http://dx.doi.org/10.1016/j.compedu.2009.08.019

[16] Ruth Kershner, Neil Mercer, Paul Warwick, Judith Kleine Staarman, Can the interactive whiteboard support young children's collaborative communication and thinking in classroom science activities?, International Journal of Computer-Supported Collaborative Learning Volume 5, Issue 4, pp 359-383, 2010 http://dx.doi.org/10.1007/s11412-010-9096-2

[17] Paul Warwick, Neil Mercer, Ruth Kershner, Judith Kleine Staarman, In the mind and in the technology: The vicarious presence of the teacher in pupil's learning of science in collaborative group activity at the interactive whiteboard, Computers \& Education, Volume 55, Issue 1, Pages 350-362, 2010 http://dx.doi.org/10.1016/j.compedu.2010.02.001

[18] Murcia, Karen; Sheffield, Rachel Australasian Journal of Educational Technology, v26 n4 spec iss p417-431, 2010

[19] Paul Warwick, Neil Mercer, Ruth Kershner, 'Wait, let's just think about this': Using the interactive whiteboard and talk rules to scaffold learning for co-regulation in collaborative science activities, Learning, Culture and Social Interaction, Volume 2, Issue 1, Pages 42-51, 2013 http://dx.doi.org/10.1016/j.lcsi.2012.12.004

[20] Daniela Stoica, Florica Paragina, Silviu Paragina, Cristina Miron, Alexandru Jipa, The interactive whiteboard and the instructional design in teaching physics, Procedia - Social and Behavioral Sciences, Volume 15, Pages 3316-3321, 2011

[21] Jung Won Hur \& Suhyun Suh, Making Learning Active with Interactive Whiteboards, Podcasts, and Digital Storytelling in ELL Classrooms, Computers in the Schools, 29:4, 320-338, 2012 http://dx.doi.org/10.1080/07380569.2012.734275

[22] Omar S. López, The Digital Learning Classroom: Improving English Language Learners' academic success in mathematics and reading using interactive whiteboard technology, Computers \& Education, Volume 54, Issue 4, Pages 901-915, 2010 http://dx.doi.org/10.1016/j.compedu.2009.09.019

[23] Higgins, S. E. 'The impact of interactive whiteboards on classroom interaction and learning in primary schools in the UK.', in Interactive whiteboards for education : theory, research and practice.Hershey, Pa: IGI Global, pp. 86-101,2010

[24] Tanner, H., Jones, S., Kennewell, S., \& Beauchamp, G. Interactive whole class teaching and interactive white Boards, Proc of the 
conference of Mathematics Education Research Group of Australasia - 28 (Melbourne), 2, 720-727, 2005

[25] Hanne Riese, Akylina Samara \& Slvi Lillejord, Peer relations in peer learning, International Journal of Qualitative Studies in Education, 25:5, 601-624,2012 http://dx.doi.org/10.1080/09518398. 2011.605078

[26] G. Fessakis, E. Gouli, E. Mavroudi, Problem solving by 5-6 years old kindergarten children in a computer programming environment: A case study, Computers \& Education, Volume 63, Pages 87-97, 2013 http://dx.doi.org/10.1016/j.compedu.2012.11.016

[27] Alex Morgan, Interactive whiteboards, interactivity and play in the classroom with children aged three to seven years, European Early Childhood Education Research Journal, 18:1, 93-104, 2010 http://dx.doi.org/10.1080/13502930903520082

[28] Ann Harlow, Bronwen Cowie \& Megan Heazlewood, Keeping in touch with learning: the use of an interactive whiteboard in the junior school, Technology, Pedagogy and Education, 19:2, 237243, 2010 http://dx.doi.org/10.1080/1475939X.2010.491234

[29] Kung-Teck Wong, Sharon Russo, Janet McDowall, "Understanding early childhood student teachers' acceptance and use of interactive whiteboard", Campus-Wide Information Systems, Vol. 30 Iss: 1, pp.4 - 16, 2013 http://dx.doi.org/10.1108/106507413 $\underline{11288788}$

[30] Paul Warwick \& Ruth Kershner, Primary teachers' understanding of the interactive whiteboard as a tool for children's collaborative learning and knowledge-building, Learning, Media and Technology, 33:4, 269-287, 2008 http://dx.doi.org/10.1080/1743988080 2496935

[31] Penelope Serow \& Rosemary Callingham, Levels of use of Interactive Whiteboard technology in the primary mathematics classroom, Technology, Pedagogy and Education, 20:2, 161-173, 2011 http://dx.doi.org/10.1080/1475939X.2011.588418

[32] Gary Beauchamp, Teacher use of the interactive whiteboard in primary schools: towards an effective transition framework, Technology, Pedagogy and Education volume 13, Issue 3,p.327-348, 2004 http://dx.doi.org/10.1080/14759390400200186

[33] Essam Bakadam, Mohammed J. Sharbib Asiri, Teachers' Perceptions Regarding the Benefits of using the Interactive Whiteboard (IWB): The Case of a Saudi Intermediate School, Procedia - Social and Behavioral Sciences, Volume 64, Pages 179-185, 2012

[34] Sue Hodge \& Bill Anderson, Teaching and learning with an interactive whiteboard: a teacher's journey, Learning, Media and Technology, 32:3, 271-282, 2007 http://dx.doi.org/10.1080/174 39880701511123

[35] Kennewell, S., Tanner, H., Jones, S. and Beauchamp, G., Analysing the use of interactive technology to implement interactive teaching. Journal of Computer Assisted Learning, 24: 61-73, 2008 http://dx.doi.org/10.1111/j.1365-2729.2007.00244.x

[36] Gary Beauchamp, Steve Kennewell, Transition in pedagogical orchestration using the interactive whiteboard, Education and Information Technologies, Volume 18, Issue 2, pp 179-191, 2013 http://dx.doi.org/10.1007/s10639-012-9230-z

[37] Gillen, J., Littleton, K., Twiner, A., Staarman, J.K. and Mercer, $\mathrm{N}$., Using the interactive whiteboard to resource continuity and support multimodal teaching in a primary science classroom. Journal of Computer Assisted Learning, 24: 348-358, 2008 http://dx.doi.org/10.1111/j.1365-2729.2007.00269.x

[38] Smith, Fay, Hardman, Frank and Higgins, Steve, 'The impact of interactive whiteboards on teacher-pupil interaction in the National Literacy and Numeracy Strategies', British Educational Research Journal, 32:3,443 - 457, 2006 http://dx.doi.org/10.1080/ 01411920600635452

[39] Bodil Sundberg, Maria Spante \& Jörgen Stenlund, Disparity in practice: diverse strategies among teachers implementing interactive whiteboards into teaching practice in two Swedish primary schools, Learning, Media and Technology, 37:3, 253-270, 2012 http://dx.doi.org/10.1080/17439884.2011.586352

[40] Neil Mercer, Paul Warwick, Ruth Kershner \& Judith Kleine Staarman, Can the interactive whiteboard help to provide 'dialogic space' for children's collaborative activity?, Language and Education, 24:5, 367-384, $2010 \quad$ http://dx.doi.org/10.1080/ 09500781003642460

[41] Tanner, H., Beauchamp, G., Jones, S. \& Kennewell, S., Interactive Whiteboards and All That Jazz: Analysing Classroom Activity with Interactive Technologies. Presented at Annual Meeting of the Mathematics Education Research Group of Australasia, 2010

[42] Neil Mercer, Sara Hennessy \& Paul Warwick, Using interactive whiteboards to orchestrate classroom dialogue, Technology, Pedagogy and Education, 19:2, 195-209, 2010 http://dx.doi.org/10.1080/1475939X.2010.491230

[43] Julia Gillen, Judith Kleine Staarman, Karen Littleton, Neil Mercer \& Alison Twiner, A 'learning revolution'? Investigating pedagogic practice around interactive whiteboards in British primary classrooms, Learning, Media and Technology, 32:3, 243-256,2007 http://dx.doi.org/10.1080/17439880701511099

[44] Victoria Armstrong, Sally Barnes, Rosamund Sutherland, Sarah Curran, Simon Mills \& Ian Thompson, Collaborative research methodology for investigating teaching and learning: the use of interactive whiteboard technology, Educational Review, 57:4, 457469, 2005 http://dx.doi.org/10.1080/00131910500279551

[45] Cathy Lewin, Bridget Somekh, Stephen Steadman, Embedding interactive whiteboards in teaching and learning: The process of change in pedagogic practice, Education and Information Technologies, Volume 13, Issue 4, pp 291-303, 2008 http://dx.doi.org/10.1007/s10639-008-9070-z

[46] Michiel Renger, Gwendolyn L. Kolfschoten, Gert-Jan de Vreede, Using Interactive Whiteboard Technology to Support Collaborative Modeling, Groupware: Design, Implementation, and Use Lecture Notes in Computer Science Volume 5411,pp 356-363, (2008)

[47] Steve Higgins , Gary Beauchamp \& Dave Miller, Reviewing the literature on interactive whiteboards, Learning, Media and Technology, 32:3, 213-225, $2007 \quad$ http://dx.doi.org/10.1080/ 17439880701511040

[48] Hall, I. and Higgins, S., Primary school students' perceptions of interactive whiteboards. Journal of Computer Assisted Learning, 21: $102-117, \quad 2005 \quad$ http://dx.doi.org/10.1111/j.13652729.2005.00118.x

[49] Kennewell, S., Reflections on the interactive whiteboard phenomenon: a synthesis of research from the UK Swansea School of Education, 2006

[50] Steve Kennewell \& Gary Beauchamp, The features of interactive whiteboards and their influence on learning, Learning, Media and Technology, 32:3, 227-241, 2007 http://dx.doi.org/10.1080/ 17439880701511073

\section{AUTHORS}

Athanasios Drigas is a Senior Researcher at N.C.S.R. Demokritos. He is the Coordinator of Telecoms Lab and founder of Net Media Lab since 1996. From 1985 to 1999 he was the Operational manager of the Greek Academic network. He has been the Coordinator of Several International Projects, in the fields of ICTs, and e-services (elearning, e-psychology, e-government, e-inclusion, eculture etc). He has published more than 200 articles, 7 books, 25 educational CD-ROMs and several patents. He has been a member of several International committees for the design and coordination of Network and ICT activities and of international conferences and journals. (e-mail: dr@iit.demokritos.gr)

George Papanastasiou is a Special Education Teacher at a public primary school in Athens. Among various research projects, in the framework of the project "Further training of educators in the use and application of ICTs in the teaching practice" under the Education and Life-Long Learning Operational Programme, Ministry of Education and Religious Affairs, he has co-authored Volume A "Theoretical Framework: The Interactive Whiteboard in the school classroom: Pedagogical Approaches - Teaching Applications" and Volume B "Educational Scenarios for the Use of the Interactive Whiteboard" (e-mail: gpapanasta@gmail.com)

Submitted 08 April 2014. Published as re-submitted by the authors 08 June 2014. 